\title{
Status Assessment, Spatial Distribution and Health Risk of Heavy Metals in Agricultural Soils Around Mining-Impacted Communities in China
}

\author{
Xiongfei Cai ${ }^{1}$, Zhibin Duan², Ji Wang * \\ ${ }^{1}$ School of Geography and Environmental Science, Guizhou Normal University, Guiyang, China \\ ${ }^{2}$ College of Resource and Environmental Engineering, Guizhou University, Guiyang, China
}

Received: 7 February 2020

Accepted: 27 June 2020

\begin{abstract}
China holds diversified mineral resources, and long term mining activities can significantly affect the enrichment of heavy metals (HMs) in agricultural soils. A systematic investigation and overall macro-evaluation on HMs contamination in agricultural soils around mining-impacted communities are urgently needed. International and China national databases were retrieved carefully with the search criteria for articles published from 2007 to 2018. Ultimately, 92 articles fit the inclusion criteria and were selected for further analysis. Based on the collected data, this study then discusses the overall status of HMs concentrations in agricultural soils around the mining-impacted communities and evaluates the pollution levels using the geoaccumulation index. To quantify the non-carcinogenic risks of HMs in soils pose to human health via oral ingestion, the recommended model was applied in the process of health risk assessment, along with Monte Carlo simulation and sensitivity analysis were performed. The results revealed that $\mathrm{HMs}$ pollution concentrations and associated ecological risks posed by $\mathrm{Cd}, \mathrm{Pb}$ and $\mathrm{Hg}$ were more serious. Meanwhile, the spatial distribution characteristics suggested that HMs (except for $\mathrm{Hg}$ ) in southern China generally were severer than those in northern China. Based on the result of human health risk assessment, $\mathrm{Cd}, \mathrm{As}$ and $\mathrm{Pb}$ posed health risks to public in some agricultural sampling sites. It should be noted that $34.02 \%, 32.99 \%$ and $30.93 \%$ of HI outputs for children, adults females and males respectively was higher than the guideline value of 1 , indicating that children were likely to have an exceptionally sensitive of exposure to environmental contaminants because the unique physiological characteristics and behavioral compared to adults. The results from this study may provide insights for policymakers to develop pollution prevention measures and management strategies in China.
\end{abstract}

Keywords: heavy metals, agricultural soils, mining-impacted communities, spatial distribution, risks assessment

*e-mail: wangji@gzu.edu.cn 


\section{Introduction}

Considering the high transfer ability and the unique biological toxicity of heavy HMs in the soil-crop system, the contamination risk of $\mathrm{HMs}$ in agriculture soils has become a great concern around the world [1-3], especially in China. According to the First National Soil Pollution Investigation of China between 2005 and 2013, the official agency issued a document in 2014 that $16.1 \%$ sample sites exceeded the guideline values in agriculture soils. Among all contaminated samples, cases related to HMs (including copper $(\mathrm{Cu})$, lead $(\mathrm{Pb})$, zinc $(\mathrm{Zn})$, cadmium $(\mathrm{Cd})$, nickel $(\mathrm{Ni})$, chromium $(\mathrm{Cr})$, mercury $(\mathrm{Hg})$, and arsenic (As)) in agricultural soils accounted for $82.4 \%$ [4].

Excessive amounts of HMs in agricultural soils are primarily resulted from the anthropogenic activities, such as mineral exploitation, metal smelting, fertilizer application, sewage irrigation and traffic emissions $[5,6]$. Due to mining activities on agricultural soils of the pollution intensity more than other pathways, it is thus urgent to investigate systematically the HMs contamination in agricultural soils from the vicinity of mining-impacted communities. Over the past decade, numerous studies have been published on HMs contamination in agricultural soils near mining areas [710]. However, most of the above-mentioned studies have been usually paid attention to the HMs contamination investigation in agricultural soils on regional scales. Although review articles have been revealed the status of HMs in agriculture soils on national scale [11-14], the research target uniformly included various categories of agriculture soils (e.g. normal farmland, greenhouse farmland, facility farmland, sewage irrigation farmland). The accumulation of HMs in agricultural soils around mining-impacted communities (mining \& smelting areas) across China was not yet examined in depth. Combine with the above analysis, in this study, scattered literatures were utilized to analyze the contamination status, spatial distribution characteristics and risk assessment of HMs in agricultural soils around the mining-impacted communities in China.

The main aims of this study are (1) to investigate the overall status of HMs concentrations in agricultural soils; (2) to analyze the contamination levels and spatial distribution of HMs based on ArcGIS software; (3) to assess human health risk based on Monte Carlo simulation and conduct cumulative probabilities and sensitivity analyses of risk exposure.

\section{Material and Methods}

\section{Literature Searching}

An overall retrieval for research papers related to HMs pollution in agricultural soils near the miningimpacted communities in China between 2007 and 2018 was made. Literature searching was performed in English and Chinese languages, and the main literature databases were carried out in the database of Web of Science Core Collection (WoSCC) and China National Knowledge Infrastructure (CNKI). Through preanalysis and comparison, we retrieved the intended

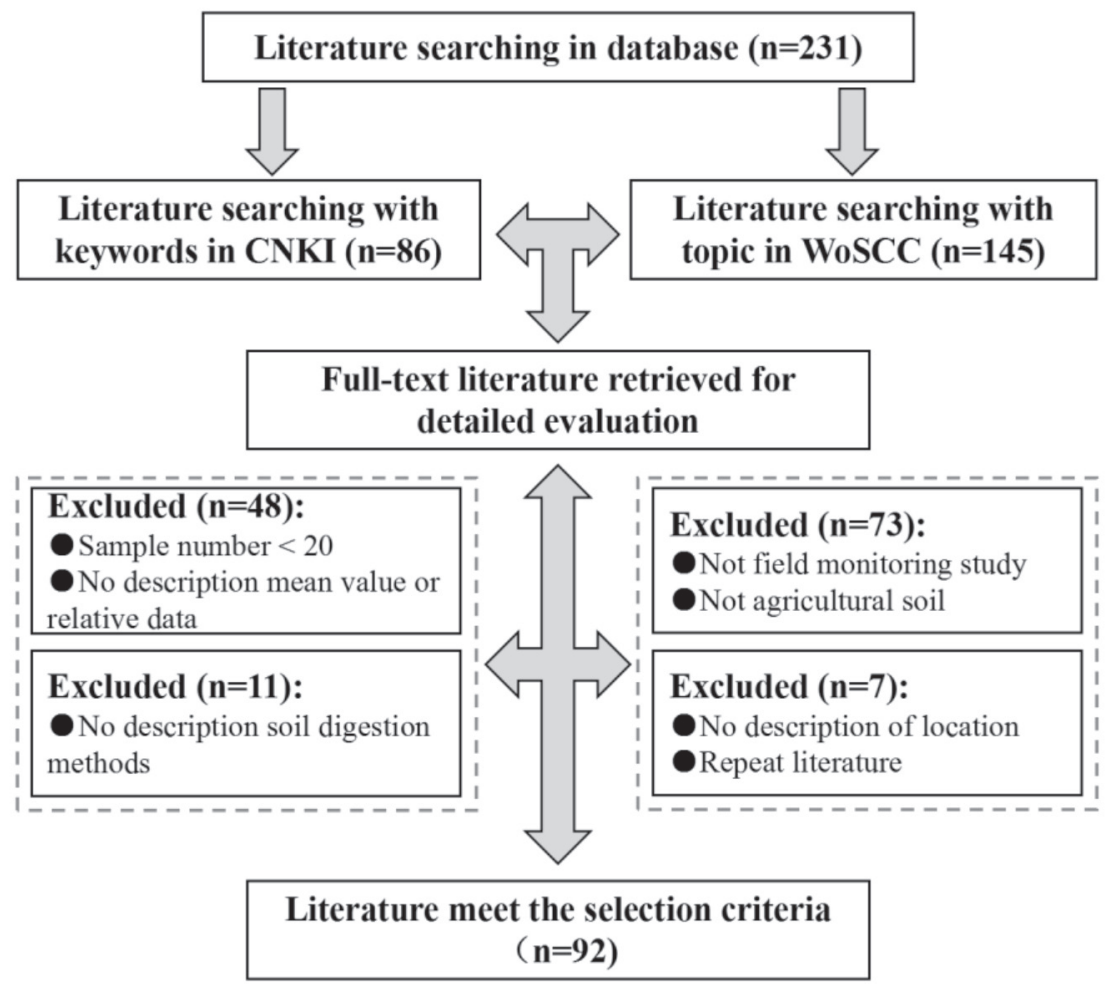

Fig. 1. Literature selection flow chart. 
keywords that appeared in the topic of the publications to ensure the accuracy of data collected. The search terms included the following: "TS (Topic) = (heavy metals* OR cadmium OR Cd OR copper OR $\mathrm{Cu}$ OR lead OR Pb OR zinc OR Zn OR nickel OR Ni OR mercury OR Hg OR arsenic OR Chromium OR Cr) AND TS $=$ (farmland soils* OR agriculture soils* OR cultivated soils*) AND TS $=$ (mining area* OR smelting area*) AND TS = (China)". A fuzzy search was performed with a "*", and the "AND" and "OR" operators were used to make our search results inclusive and restrictive. Eventually, a total of 228 relevant literatures were searched and downloaded from the database of WoSCC and CNKI.

\section{Literature Selection}

To be included in unified analysis, the literature that did not meet the following mentioned criteria were excluded: (i) it must be field monitoring study, and topsoil samples were collected in agricultural soils in depth of $0-20 \mathrm{~cm}$ from mining-impacted communities; (ii) $>20$ soils samples were selected; (iii) it should obtain the mean values of HMs or relevant data, or it could be calculated with the sample-number-weighted mean when the mean value was not directly stated; (iv) soils should be digested with acceptable methods such as $\mathrm{HCl}-\mathrm{HNO}_{3}-\mathrm{HF}-\mathrm{HClO}_{4}, \mathrm{HNO}_{3}-\mathrm{HClO}_{4}-\mathrm{HF}, \mathrm{HNO}_{3}-$ $\mathrm{HClO}_{4}-\mathrm{HCl}$, aqua regia digestion and other scientific digestion methods, and the samples were determined by atomic fluorescence spectrophotometry or inductively coupled plasma atomic emission spectrometry; (v) it must be remove duplicate publication literature. The criterion for the literature selection is shown in Fig. 1. Based on the eligibility criteria, 92 eligible were selected.

\section{Data Extraction}

We directly extracted data from each eligible literature included: (i) authors, title, and publishing year; (ii) administrative region, study area, and longitude and latitude; (iii) number of sampling sites; (iv) the types of the examined mining-impacted communities (coal mine, lead-zinc mine, multi-metal mine, etc.); (v) the mean value of HMs content. The relevant data from 76 mining areas and 12 smelting areas were extracted, and the cumulative quantity of obtained sampling sites of $\mathrm{Cd}, \mathrm{Cr}, \mathrm{Hg}, \mathrm{Pb}, \mathrm{As}, \mathrm{Cu}, \mathrm{Zn}$ and $\mathrm{Ni}$ was 8403,5888 , 4458, 7692, 5931, 7188, 7399 and 3592, respectively.

\section{Geo-Accumulation Index}

The Geo-accumulation index $\left(\mathrm{I}_{\text {geo }}\right)$ was developed by Muller [15] and has been widely applied in assessment soils contamination [16]. In this study, we used the $\mathrm{I}_{\text {geo }}$ to determine HMs contamination in soil. $\mathrm{I}_{\text {geo }}$ was calculated using the following formula:

$$
I_{\text {geo }}=\log _{2}\left[C_{n} /\left(1.5 B_{n}\right)\right]
$$

...where $C_{n}$ stands for the measured concentration of the HMs in the examined soils $(\mathrm{mg} / \mathrm{kg})$ and $B_{n}$ represents the geochemical background values of the HMs in the examined soils for different provinces. The Geoaccumulation index is categorized into seven classes based on the severity of contamination ranging from normal to heavy contamination (Table 1).

\section{Health Risk Assessment}

Considering the differences in behavioral and physiological, the present review divided the residents who lived in close proximity to the examined miningimpacted areas into three groups: adult males, adult females and children. Large numbers of researches indicated that incidental oral ingestion and dermal absorption through contact with soils particulates appeared to be the primary pathway among the potential exposure routes in the mining areas, but others indeed found that soils ingestion contributed the most to health risk of HMs exposure and played the most important roles among the exposure routes [17, 18]. Thus, this study only evaluated the health risk via oral ingestion of soils. The non-carcinogenic risk via soils ingestion was calculated as follows:

$$
\begin{gathered}
A D I_{\text {ing }}=C \times \frac{\operatorname{IngR} \times E F \times E D}{B W \times A T} \times 10^{-6} \\
H Q=\frac{A D I_{\text {ing }}}{R f D}
\end{gathered}
$$

$H I=H Q_{C d}+H Q_{C r}+H Q_{H g}+H Q_{A s}+H Q_{P b}+H Q_{C u}+H Q_{Z n}+H Q_{N i}$

...where $C$ is the HMs concentration in the soils $(\mathrm{mg} / \mathrm{kg}), \mathrm{ADI}_{\text {ing }}$ represents the estimated daily intake of the average daily intake of soils HMs by oral ingestion (mg/kg/day). HQ represents the target hazard quotients which is used to assess the potential non-carinogenic

Table 1 . The criteria for grades of the geo-accumulation index.

\begin{tabular}{|c|c|c|}
\hline Class & Value & Soil quality \\
\hline 0 & $\mathrm{I}_{\mathrm{geo}} \leq 0$ & Practically uncontaminated \\
\hline 1 & $0<\mathrm{I}_{\mathrm{geo}} \leq 1$ & $\begin{array}{c}\text { Uncontaminated to moderately } \\
\text { contaminated }\end{array}$ \\
\hline 2 & $1<\mathrm{I}_{\mathrm{geo}} \leq 2$ & Moderately contaminated \\
\hline 3 & $2<\mathrm{I}_{\mathrm{geo}} \leq 3$ & Moderately to heavily contaminated \\
\hline 4 & $3<\mathrm{I}_{\mathrm{geo}} \leq 4$ & Heavily contaminated \\
\hline 5 & $4<\mathrm{I}_{\mathrm{geo}} \leq 5$ & Heavily to extremely contaminated \\
\hline 6 & $5<\mathrm{I}_{\mathrm{geo}}$ & Extremely contaminated \\
\hline
\end{tabular}


Table 2. Parameter values in average daily dose calculation of HMs.

\begin{tabular}{|c|c|c|c|c|c|}
\hline \multirow{2}{*}{ Parameter } & \multirow{2}{*}{ Symbol } & \multirow{2}{*}{ Unit } & \multicolumn{3}{|c|}{ Value } \\
\hline & & & Children & Adult males & Adults females \\
\hline Ingestion rate & IngR & $\mathrm{mg} /$ day & $\mathrm{LN}(24 \pm 4)$ & $\mathrm{LN}(50 \pm 5)$ & $\mathrm{LN}(50 \pm 5)$ \\
\hline Exposure frequency & $\mathrm{EF}$ & day/year & TRI $(180,345,365)$ & TRI $(180,345,365)$ & TRI $(180,345,365)$ \\
\hline Exposure duration & ED & years & POI (6) & POI (30) & POI (30) \\
\hline Average body weight & BW & $\mathrm{kg}$ & TRI $(5.25,29.3,56.8)$ & $\mathrm{LN}(67.55 \pm 8.72)$ & LN $(57.59 \pm 8.03)$ \\
\hline $\begin{array}{l}\text { Averaging time for non-carcino- } \\
\text { genic }\end{array}$ & AT & days & POI $(365 \times E D)$ & POI $(365 \times E D)$ & POI $(365 \times E D)$ \\
\hline \multirow{8}{*}{ Reference dose $(R f D)$} & As & \multirow{8}{*}{$\mathrm{mg} / \mathrm{kg} /$ day } & \multicolumn{3}{|c|}{ TRI $(0.0003,0.0003,0.0008)$} \\
\hline & $\mathrm{Cd}$ & & \multicolumn{3}{|c|}{ TRI $(0.001,0.001,0.04)$} \\
\hline & $\mathrm{Cr}$ & & \multicolumn{3}{|c|}{ TRI $(0.003,0.003,2.5)$} \\
\hline & $\mathrm{Ni}$ & & \multicolumn{3}{|c|}{ TRI $(0.02,0.02,5)$} \\
\hline & $\mathrm{Zn}$ & & \multicolumn{3}{|c|}{ TRI $(0.3,0.3,0.91)$} \\
\hline & $\mathrm{Hg}$ & & \multicolumn{3}{|c|}{ TRI $(0.0003,0.0003,0.0008)$} \\
\hline & $\mathrm{Pb}$ & & \multicolumn{3}{|c|}{ TRI $(0.0035,0.0035,0.009)$} \\
\hline & $\mathrm{Cu}$ & & \multicolumn{3}{|c|}{ TRI $(0,0.04,0.04)$} \\
\hline
\end{tabular}

LN, Lognormal distribution. TRI, Triangular distribution. POI, Point distribution.

risk of individual HMs, and $\mathrm{HI}$ represents the overall potential non-carcinogenic risk posed by multiple HMs in the study. The other input variables and values (i.e., IngR, EF, ED, BW, AT, and RfD) are given in Table 2. If the $\mathrm{HQ}$ or $\mathrm{HI}<1$ indicates minimal health effects, whereas the HQ or $\mathrm{HI}>1$ indicates a probability of adverse health effects.

Uncertainty always exists in risk assessment process $[19,20]$, especially when the uncertainty arises owing to lack of precise knowledge, the variability of toxic response for individuals and the variability of environmental systems [21, 22]. The Monte Carlo simulation via Oracle Crystal ball software was employed in this study to minimize the uncertainties associated with health risk analysis process. The distribution of input variables for different population groups in the Monte Carlo simulation are shown in Table 2. To ensure the reliability of the results, the model was externally run 10,000 times in each simulation process. In addition, conduct cumulative probabilities and sensitivity were introduced to identify the variable that affected the distribution of risk outcome and calculate the contribution of each input variable to the probabilistic health risk.

\section{Results and Discussion}

\section{Overall Status of HMs Concentrations in Agricultural Soils}

The statistical information about the selected HMs concentrations in agricultural soils around the mining- impacted communities is shown in Table 3. It is clear to see that the mean concentration of each metal exceeded the corresponding background value for soils in China, and concentrations of the collected samples for $\mathrm{Cd}, \mathrm{Hg}$ and $\mathrm{Cu}$ nearly exceeded the corresponding reference concentration for $97.8 \%, 97.7 \%$ and $95.3 \%$, respectively. The mean concentrations of $\mathrm{Cd}, \mathrm{Cr}, \mathrm{Hg}, \mathrm{As}, \mathrm{Pb}, \mathrm{Cu}$, $\mathrm{Zn}$ and Ni were about 15.66, 0.85, 0.55, 2.53, 2.98, 1.16, 2.19 and 0.82 times greater than the corresponding national standard values in agricultural soils (GB 15618-2018), respectively. The highest proportion of surpassing the national standard values was found in $\mathrm{Cd}(88.8 \%)$, indicating that mining activities introduced a considerable amount of $\mathrm{Cd}$ into agricultural soils, followed by $\mathrm{Pb}(50.6 \%), \mathrm{Zn}$ (47.2\%), As (39.7\%), $\mathrm{Cu}$ (29.4\%), $\mathrm{Cr}$ (13.2\%), $\mathrm{Hg}(11.4 \%)$ and $\mathrm{Ni}(7.3 \%)$. According to the above analyses, agricultural soils near mining-impacted areas was contaminated the most by $\mathrm{Cd}$. Previous reports have demonstrated that high Cd concentration in agricultural soils around mining areas was mainly stemmed from the mining activities, such as mineral excavation, ore transportation, tailing disposition, and smelting activities that took place in those areas were led $\mathrm{Cd}$ to flow and accumulate into soils [23-27]. Cadmium in soils can be taken up by the roots system of agricultural crops and transported to the above-ground organs. Consumption of agricultural crops grown in Cd-contaminated soils is an important $\mathrm{Cd}$ exposure route to human beings and caused extensive threats to human health. Therefore, a series of contamination control and remediation measures should be adopted in China to make significant efforts to address soils $\mathrm{Cd}$ contamination. 
Table 3. The HMs concentrations ( $\mathrm{mg} / \mathrm{kg}$ ) and the percentile concentrations (\%) for the eight HMs from the examined the miningimpacted communities.

\begin{tabular}{|c|c|c|c|c|c|c|c|c|}
\hline & $\mathrm{Cd}$ & $\mathrm{Cr}$ & $\mathrm{Hg}$ & $\mathrm{As}$ & $\mathrm{Pb}$ & $\mathrm{Cu}$ & $\mathrm{Zn}$ & $\mathrm{Ni}$ \\
\hline Minimum value & 0.03 & 3.07 & 0.04 & 4.31 & 5.95 & 9.30 & 22.42 & 4.55 \\
\hline Maximum value & 68.64 & 3353.6 & 14.11 & 1051.44 & 3204.00 & 997.00 & 2576.00 & 1556.80 \\
\hline Mean value & 4.70 & 170.09 & 1.33 & 76.00 & 357.11 & 115.65 & 547.99 & 82.44 \\
\hline BVSC $^{\text {a }}$ & 0.097 & 61.00 & 0.065 & 11.20 & 26.00 & 22.60 & 74.20 & 26.90 \\
\hline SEQRCSSCA $^{\mathrm{b}}$ & 0.30 & 200.00 & 2.40 & 30.00 & 120.00 & 100.00 & 250.00 & 100.00 \\
\hline SSEQRCSSCA & $88.8 \%$ & $13.2 \%$ & $11.4 \%$ & $39.7 \%$ & $50.6 \%$ & $29.4 \%$ & $47.2 \%$ & $7.3 \%$ \\
\hline BVSC $\sim$ SEQRCSSCA $<$ BVSC & $9.0 \%$ & $60.3 \%$ & $86.3 \%$ & $49.2 \%$ & $37.1 \%$ & $65.9 \%$ & $42.5 \%$ & $63.4 \%$ \\
\hline
\end{tabular}

${ }^{\text {a } B a c k g r o u n d ~ v a l u e s ~ f o r ~ s o i l s ~ i n ~ C h i n a, ~ i t ~ i s ~ d e r i v e d ~ f r o m ~ C h i n a ~ N a t i o n a l ~ E n v i r o n m e n t a l ~ M o n i t o r i n g ~ C e n t e r . ~}$

${ }^{\mathrm{b}}$ Soils environmental quality risk control standard for soils contamination of agricultural land with $6.5<\mathrm{pH} \leq 7.5$ (GB 15618-2018).

\section{Geo-Accumulation Classification of HMs}

Table 4 is presented for the class distribution of geo-accumulation indices for the selected HMs. The results showed that about $85.07 \%$ and $92.5 \%$ of all the sampling sites for $\mathrm{Cr}$ and $\mathrm{Ni}$ were fallen below Class 2. However, the $\mathrm{I}_{\text {geo }}$ values for $\mathrm{Cd}$ and $\mathrm{Pb}$ ranged from Class 0 to Class 6, among which, $23.60 \%$ and $5.62 \%$ of the sampling sites for this two HMs belong to Class 6. Most of the $\mathrm{I}_{\mathrm{geo}}$ values for other HMs were laid below Class 4 , among which, $>60 \%$ of the sampling sites for $\mathrm{As}$ and $\mathrm{Cu}$ were lower than Class 2, while $20.93 \%$ of the sampling sites for $\mathrm{Hg}$ belonged to Class 6. Based on the above analysis, although the selected HMs pollution levels varied among the examined sites, agricultural soils near the mining-impacted communities have been more severely polluted by $\mathrm{Cd}$ and $\mathrm{Hg}$. This result was in the lines of a previous review by Yang et al. [28], which revealed that $>50 \%$ of the soils sampling sites in agricultural regions were above Class 1 for $\mathrm{Cd}$ and $\mathrm{Hg}$.

The spatial distribution of HMs which was based on the standard classes of $I_{\text {geo }}$ is demonstrated in
Fig. 2. Higher $\mathrm{I}_{\text {geo }}$ values of $\mathrm{Cd}$ from the collected database were dispersed over a wide area, including Yunnan, Guangdong, Guangxi, Hunan, Henan, Sichuan, Liaoning, Gansu and Fujian provinces. Furthermore, as can be observed from the picture, $\mathrm{Cd}$ pollution in agricultural soils was more serious in the south than in north, especially pollution regions in the southwest and central-south were more extensive. Extremely contaminated for $\mathrm{Pb}\left(\mathrm{I}_{\text {geo }}>5\right)$ were mainly situated in the southwest China as well as the junction of Guangxi, Guangdong and Hunan three provinces. This may be caused by the fact that these provinces contained abundant with mineral resources, such as Hunan and Guangxi province are known as the homes of non-ferrous metals, Ganluo $\mathrm{Pb}-\mathrm{Zn}$ mine in Sichuan province is the largest $\mathrm{Pb}-\mathrm{Zn}$ reservoir in Western China, Hezhang in Guizhou province is a zinc smelting county with a history of over 100 years, Huize in Yunnan province is a typical representative of large $\mathrm{Pb}-\mathrm{Zn}$ mine. Similarly, clear spatial distribution of $\mathrm{Zn}$ was apparent, with soils $\mathrm{Zn} \mathrm{I}_{\text {geo }}$ values in south China nearly higher than other areas. However, the $\mathrm{I}_{\text {geo }}$ values of spatial distribution illustrated that the highest

Table 4. Class distribution of geo-accumulation index of HMs in agricultural soils near mining-impacted communities.

\begin{tabular}{|c|c|c|c|c|c|c|c|c|}
\hline Class & $\mathrm{Cd}$ & $\mathrm{Cr}$ & $\mathrm{Hg}$ & $\mathrm{As}$ & $\mathrm{Pb}$ & $\mathrm{Cu}$ & $\mathrm{Zn}$ & $\mathrm{Ni}$ \\
\hline 0 & $4.49 \%$ & $59.70 \%$ & $11.63 \%$ & $42.86 \%$ & $24.72 \%$ & $30.59 \%$ & $25.29 \%$ & $55.00 \%$ \\
\hline 1 & $12.36 \%$ & $25.37 \%$ & $11.63 \%$ & $20.63 \%$ & $16.85 \%$ & $31.76 \%$ & $21.84 \%$ & $37.50 \%$ \\
\hline 2 & $22.47 \%$ & $7.46 \%$ & $23.26 \%$ & $12.70 \%$ & $19.10 \%$ & $24.71 \%$ & $19.54 \%$ & $5.00 \%$ \\
\hline 3 & $10.11 \%$ & $5.97 \%$ & $23.26 \%$ & $12.70 \%$ & $19.10 \%$ & $24.71 \%$ & $19.54 \%$ & $0.00 \%$ \\
\hline 4 & $11.24 \%$ & $0.00 \%$ & $9.30 \%$ & $9.52 \%$ & $13.48 \%$ & $4.71 \%$ & $17.24 \%$ & $0.00 \%$ \\
\hline 5 & $15.73 \%$ & $0.00 \%$ & $0.00 \%$ & $0.00 \%$ & $4.49 \%$ & $0.00 \%$ & $4.60 \%$ & $0.00 \%$ \\
\hline 6 & $23.60 \%$ & $1.49 \%$ & $20.93 \%$ & $1.59 \%$ & $5.62 \%$ & $2.35 \%$ & $0.00 \%$ & $2.52 \%$ \\
\hline
\end{tabular}



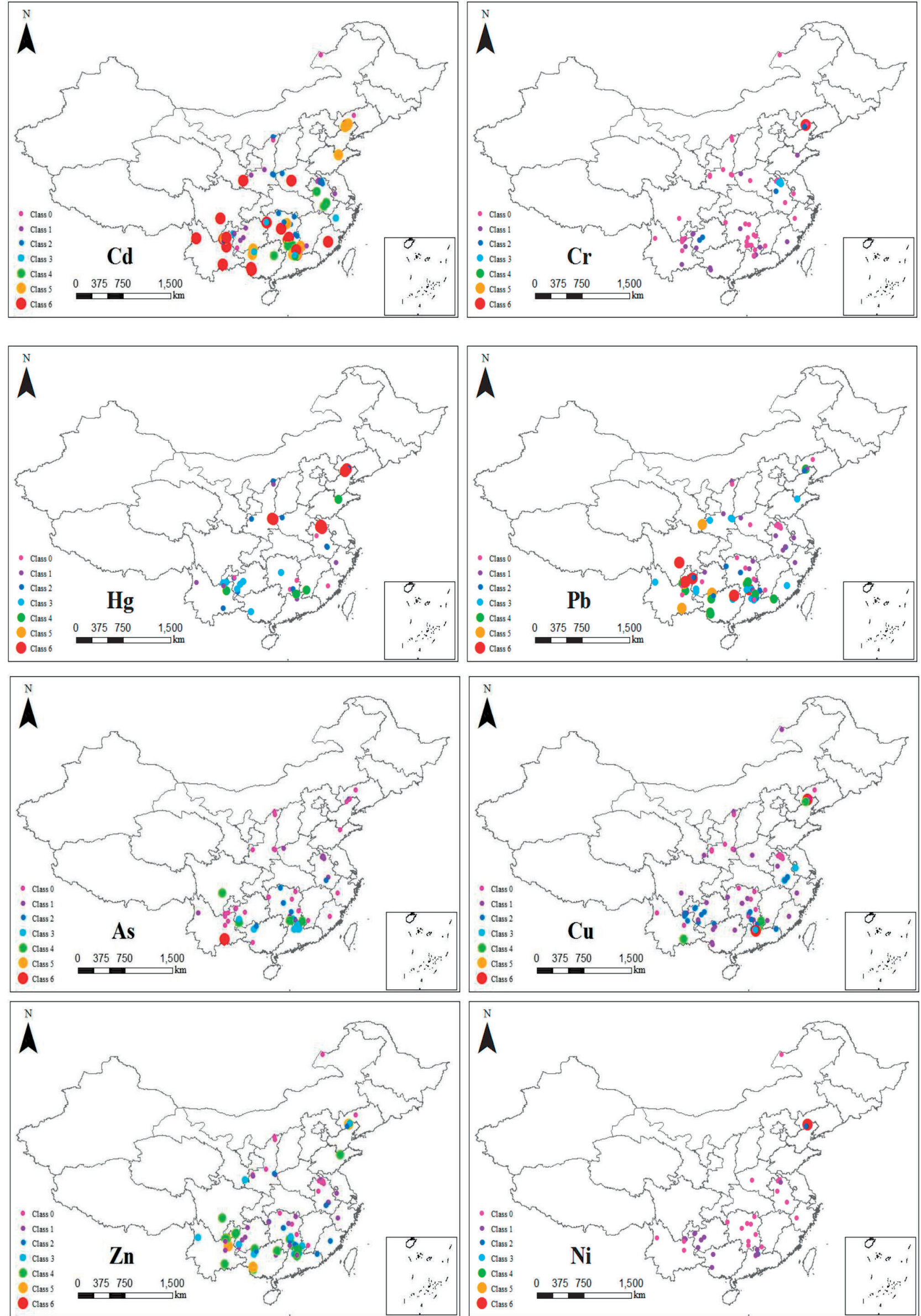

Fig. 2. Spatial distribution of HMs in agriculture soils near examined mining-impacted areas based on contamination classes. 

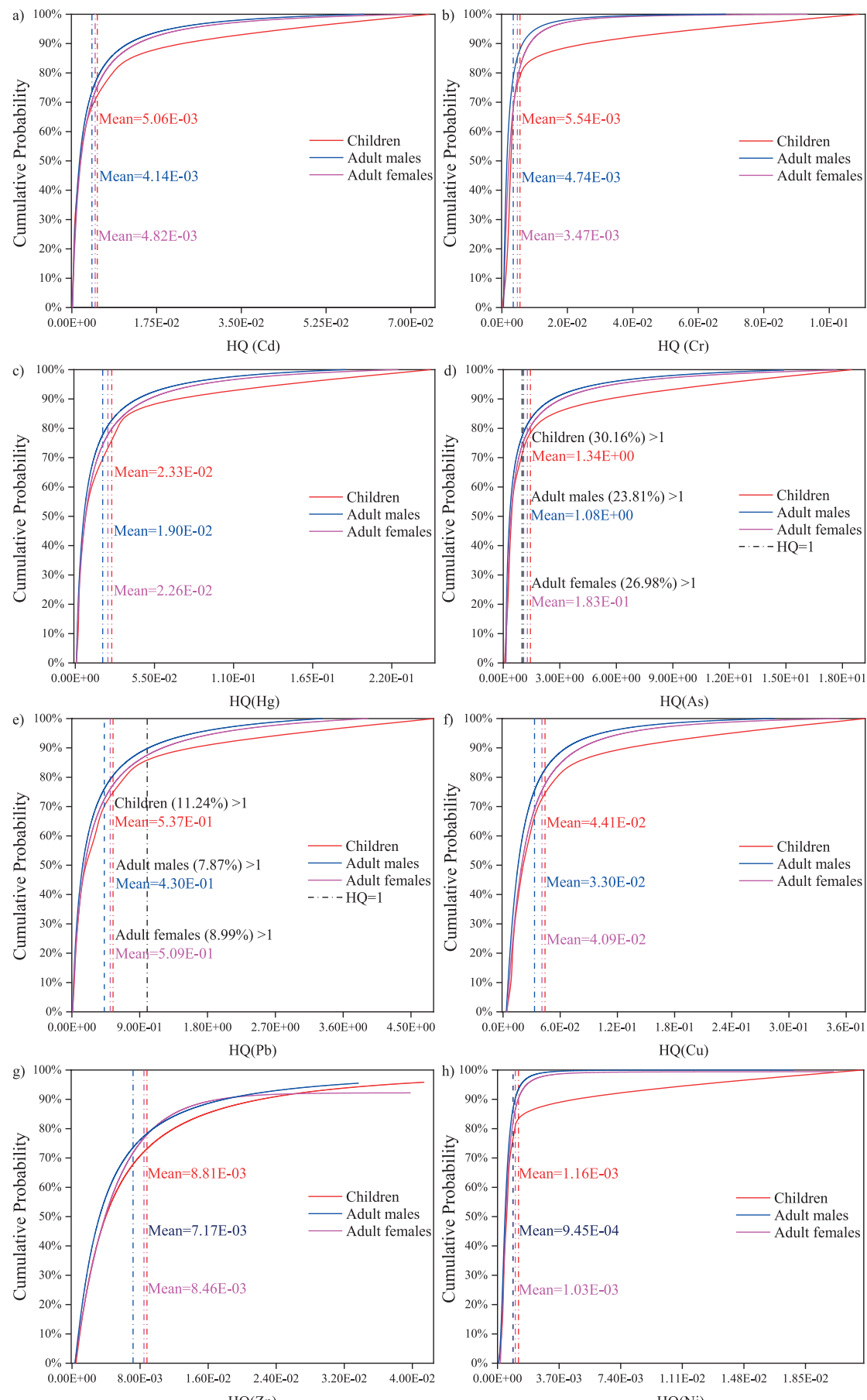

$\mathrm{HQ}(\mathrm{Cu})$
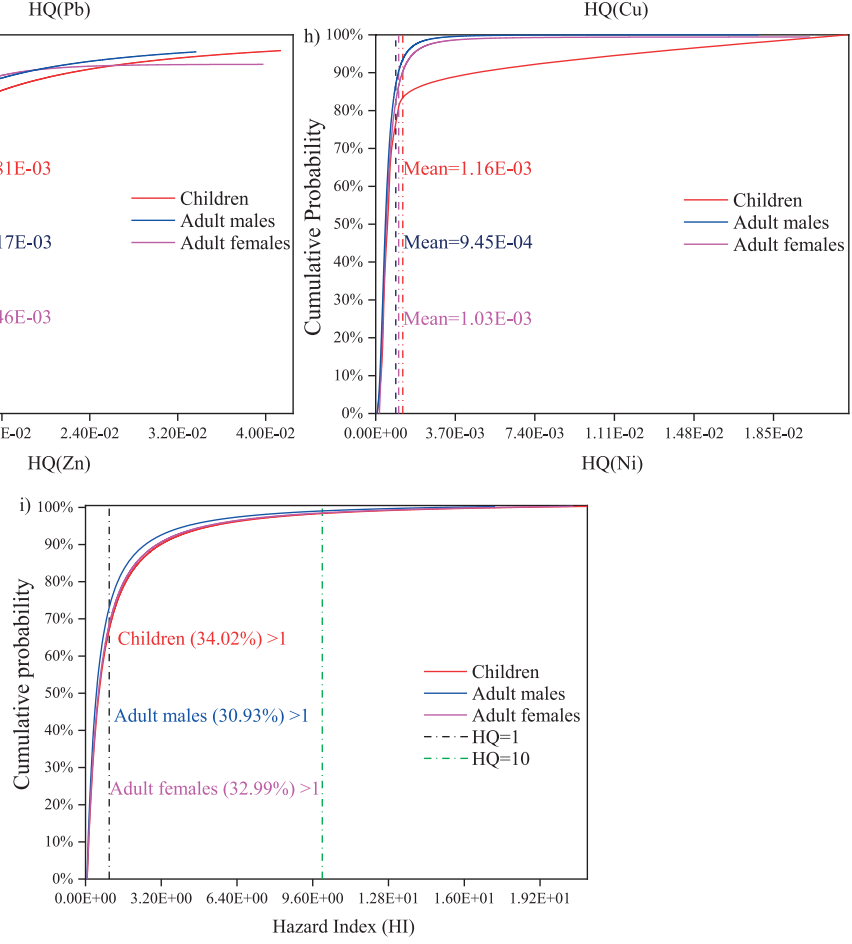

Fig. 3. Cumulative probability of hazard quotient (HQ) posed by a) $\mathrm{Cd}$, b) $\mathrm{Cr}$, c) $\mathrm{Hg}$, d) $\mathrm{As}$, e) $\mathrm{Pb}, \mathrm{f}$ ) $\mathrm{Cu}$, g) $\mathrm{Zn}$, h) Ni and cumulative probability of i) hazard index (HI) for the different population groups. (The red, blue and magenta solid vertical lines presented the mean values for children, adult males and females, respectively. The black and green dashed vertical lines presented the guideline values that of 1 and 10 , respectively). 
$\mathrm{I}_{\text {geo }}$ values of $\mathrm{Cr}$, $\mathrm{Ni}$ and $\mathrm{Cu}$ were located in Huludao city in Liaoning province, the finding was relevant to the intensive metal-smelting industry [29]. In addition, another hotspot for $\mathrm{Cu}$ was observed in Dabaoshan mine in Guangzhou province, which is the largest multi-metal mine in southern China. For As, the highest $I_{\text {geo }}$ value was located in Gejiu in Yunnan province due to the Sn-mineral exploitation and smelting activities. Because few sampling sites for $\mathrm{Hg}$ in examined miningimpacted communities, the higher $\mathrm{I}_{\mathrm{geo}}$ values were only detected in Liaoning Huludao molybdenum mine, Shaanxi Xiaoqinling gold mine and Anhui Suzhou coal mining area. Based on the above analysis, higher $\mathrm{I}_{\text {geo }}$ values of the selected HMs except for $\mathrm{Hg}$ were mainly distributed in southern China, such as the YunnanGuizhou plateau, the karst regions in southern China and the southern part regions of the Yangtze River.

\section{Non-Carcinogenic Risk Assessment}

Non-carcinogenic health risk results of soil ingestion exposure to the selected HMs in agriculture soils around examined mining-impacted communities are presented in Fig. 3. It appeared from Fig. 3(a-g) that the mean HQ values of the investigated HMs for the three population groups all lower than 1, except for As. There is a clear trend of the mean HQ values decreased in the following order: $\mathrm{As}>\mathrm{Pb}>\mathrm{Cu}>\mathrm{Hg}>\mathrm{Zn}>\mathrm{Cr}>\mathrm{Cu}>\mathrm{Ni}$ for the three population groups. Among the investigated $\mathrm{HMs}$, human exposure to $\mathrm{As}$ and $\mathrm{Pb}$ were significantly higher than the other HMs due to their low RfD values ( $R f D$ is the reference oral dose available for $\mathrm{HMs}$ ). In the meantime, from the data in Fig. 3(d-e), it is apparent that $30.16 \%, 26.98 \%$ and $23.81 \%$ of HQ outputs of As for children, adults females and males, respectively, exceeded 1, $11.24 \%, 8.99 \%$ and $7.87 \%$ of HQ outputs for children, adults females and males respectively exceeded 1 for $\mathrm{Pb}$, suggesting that $\mathrm{As}$ and $\mathrm{Pb}$ contamination in part of Chinese agriculture soils around mining-impacted communities might pose a risk

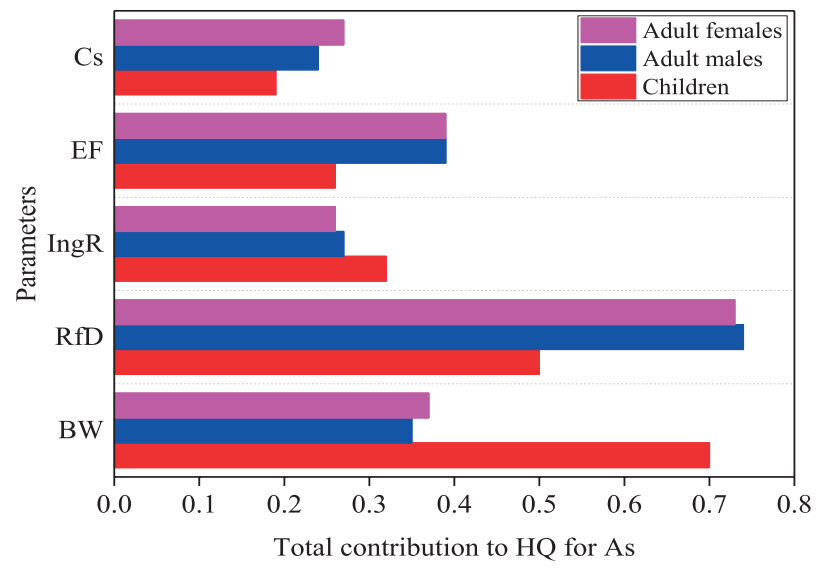

Fig. 4. Sensitivity ratio of average body weight (BW), reference oral dose (RfD), ingestion rate (IngR), exposure frequency (EF) and concentrations $(C)$ for hazard quotient (HQ). for human health. Sensitivity analyses were adopted by applying the HQ values of As (the worst-case scenario) (Fig. 4), it is evident that the average body weight (BW) and ingestion rate (IngR) for children had relatively higher contribution than those for adults, with BW contributed the most. The result was in the lines of previous studies that children were likely to have an exceptionally sensitive of exposure to environmental contaminants per unit body weight due to unique physiological characteristics and behavioral [30, 31], such as hand-finger sucking, which is often considered to be the critical exposure routes of soils HMs might trigger adverse effects on health for children [32, 33]. Relying on the above analyses, it can be served as an evidence to explain the major cause why HQ outputs for children were far higher than those for adults.

Based on the cumulative probabilities of hazard index (HI) of the exposed three populations groups, Fig. 3i) shown that the percentage of the examined mining-impacted areas for adult males whose HI values was higher than the guideline value of 1 , between 0 and 1 , and between 1 and 10 were about $30.93 \%, 69.07 \%$ and $29.90 \%$, respectively. For adult females, approximately $32.99 \%, 67.01 \%, 30.93 \%$ were the percentage of the examined mining-impacted areas whose HI values were higher than 1, between 0 and 1, and between 1 and 10 . However, HI value for above 1 accounted for $34.02 \%$ for children, 65.98\% laid between 0 and 1, and 31.96\% laid between 1 and 10. On the basis of the above analyses, it can be concluded that part of agricultural soils near the mining-impacted areas posed potentially noncarcinogenic risk to the public. In comparison to the other two groups, children were more susceptible to the investigated HMs in soils than adults. Similar findings were consistent with previous studies by Man et al. [34] and Chen et al. [35]. Thus, the potential health risk to young children who living in the vicinity of miningimpacted areas resulted from exposure to soils via ingestion cannot be neglected.

\section{Limitations and Uncertainties}

Firstly, the distribution of the examined miningimpacted communities in this study cannot fully represent the overall pollution situation of $\mathrm{HMs}$ in agriculture soils around the mining-impacted communities across China due to the lack of relevant data in other provinces. Besides, owing to most previous studies tend to conduct in more polluted sites, which may influence the pollution levels and spatial distribution of the selected heavy metals. Secondly, some discrepancies in both digestion methods and analytical techniques from the eligible literature may impact the consistency of HMs pollution levels and the assessment results. However, these discrepancies are not be big enough to influence the general research results because the experimental methods are in accordance with the corresponding specifications and national standards and are all widely accepted by the scientific community. 
Moreover, the choice of exposure parameters control the reliability of the assessment results. In order to more accurately and realistically estimate the health risks for the different population groups, some existing parameters (e.g. BW, IngR, EF and ED) in present study were derived from relevant regulations and literature conducted within China, while the toxicity parameters mainly cited foreign sources. Ever so, we cannot fully eliminate the uncertainty of the assessment results caused by exposure parameters. Lastly, agricultural soils properties (e.g. pH, Eh, CEC, and SOM) affect HMs absorption and concentrations in soils. It should be noted that the above chemical properties of soils cannot all obtained in the selected literature, thus, we have not been discussed in this study because of the limited data sources.

\section{Conclusions}

This study gives a description of the overall contamination of HMS in agriculture soils around the mining-impacted communities across China and their ecological and health risk assessment. Based on the results of this study, it is apparent that the selected HMs pollution levels varied among the examined sites. In particular, agriculture soils are seriously polluted by $\mathrm{Cd} \mathrm{Pb}$ and $\mathrm{Hg}$. Additionally, the spatial distribution characteristics suggested that HMs pollution except for $\mathrm{Hg}$ were more serious in southern China than northern regions. Moreover, agriculture soils contamination by HMs emitted from mining activities continues to pose health risk to children and adults, especially to $\mathrm{As}$ and $\mathrm{Pb}$ should be paying more attention and regulation owing to their high non-carcinogenic health risk.

\section{Acknowledgements}

This work was financially supported by the Project of Science and Technology Foundation of Guizhou Province (No.[2017]2580 and No.[2019]1231), the Project of Innovation in Postgraduate Education in Guizhou (YJSCXJH[2019]038), and the Project of Graduate Innovation Foundation in Guizhou University (No.2019075).

\section{Conflict of Interest}

The authors declare no conflict of interest.

\section{References}

1. CHEN Y., HU W., HUANG B., WEINDORF D.C., RAJAN N., LIU, X., NIEDERMANN S. Accumulation and health risk of heavy metals in vegetables from harmless and organic vegetable production systems of China. Ecotoxicology and Environmental Safety, 98, 324, 2013.

2. KHAN A., KHAN, S., KHAN M.A., QAMAR Z., WAQAS M. The uptake and bioaccumulation of heavy metals by food plants, their effects on plants nutrients, and associated health risk: a review. Environmental Science and Pollution Research, 22, 13772, 2015.

3. SHARAFI K., YUNESIAN M., NODEHI R.N., MAHVI A.H., PIRSAHEB M. A systematic literature review for some toxic metals in widely consumed rice types (domestic and imported) in Iran: Human health risk assessment, uncertainty and sensitivity analysis. Ecotoxicology and Environmental Safety, 176, 64, 2019.

4. CHEN R., DE SHERBININ A., YE C., SHI G. China's soil pollution: farms on the frontline. Science, 344, 691, 2014.

5. LIU G., TAO L., LIU X., HOU J., WANG A., LI R. Heavy metal speciation and pollution of agricultural soils along Jishui River in non-ferrous metal mine area in Jiangxi Province, China. Journal of Geochemical Exploration, 132, 156, 2013.

6. LIU G., YU Y., HOU J., XUE W., LIU X., LIU Y., WANG W., ALSAEDIl A., HAYAT T., LIU Z. An ecological risk assessment of heavy metal pollution of the agricultural ecosystem near a lead-acid battery factory. Ecological Indicators, 47, 210, 2014.

7. ZHENG N., WANG Q., ZHENG D. Health risk of $\mathrm{Hg}, \mathrm{Pb}$, $\mathrm{Cd}, \mathrm{Zn}$, and $\mathrm{Cu}$ to the inhabitants around Huludao zinc plant in China via consumption of vegetables. Science of the Total Environment, 383, 81, 2007.

8. LI J., LU Y., YIN W., GAN H., ZHANG C., DENG X., LIAN J. Distribution of heavy metals in agricultural soils near a petrochemical complex in Guangzhou, China. Environmental Monitoring and Assessment, 153, 365, 2009.

9. XU D., ZHOU P., ZHAN J., GAO Y., DOU C., SUN Q. Assessment of trace metal bioavailability in garden soils and health risks via consumption of vegetables in the vicinity of Tongling mining area, China. Ecotoxicology and Environmental Safety, 90, 103, 2013.

10. CAI L., WWANG Q., WEN H., LUO J., WANG S. Heavy metals in agricultural soils from a typical township in Guangdong Province, China: Occurrences and spatial distribution. Ecotoxicology and Environmental Safety, 168, 184, 2019.

11. ZHANG X., ZHONG T., CHEN D., CHENG M., LIU L., ZHANG X., LI X. Assessment of arsenic (As) occurrence in arable soil and its related health risk in China. Environmental Geochemistry and Health, 38, 691, 2016.

12. HUANG Y., WANG L., WANG W., LI T., HE Z., YANG $X$. Current status of agricultural soil pollution by heavy metals in China: A meta-analysis. Science of the Total Environment, 468, 843, 2019.

13. SHI T., MA J., ZHANG Y., LIU C., HU Y., GONG Y., WU X., JU T., HOU H., ZHAO L. Status of lead accumulation in agricultural soils across China (19792016). Environment International, 129, 35, 2019.

14. SHI T., ZHANG Y., GONG Y., MA J., WEI H., WU X., ZHAO L., HOU H. Status of cadmium accumulation in agricultural soils across China (1975-2016): From temporal and spatial variations to risk assessment. Chemosphere, 230, 136, 2019.

15. MULLER G. Index of geoaccumulation in sediments of the Rhine River. Geological Journal, 2, 108, 1969. 
16. LOSKA K., WIECHULA D., KORUS I. Metal contamination of farming soils affected by industry. Environment Pollution, 30, 159, 2004.

17. RAMIREZ-ANDREOTTA M.D., BRUSSEAU M.L., BEAMER P., MAIER R.M. Home gardening near a mining site in an arsenic-endemic region of Arizona: assessing arsenic exposure dose and risk via ingestion of home garden vegetables, soils, and water. Science of the Total Environment, 454, 373, 2013.

18. LI N., KANG Y., PAN W., ZENG L., ZHANG Q., LUO J. Concentration and transportation of heavy metals in vegetables and risk assessment of human exposure to bioaccessible heavy metals in soil near a waste-incinerator site, south China. Science of the Total Environment, 521, 144, 2015.

19. GLORENNECl P., BEMRAH N., TARD A., ROBIN A., BOT B.L., BARD D. Probabilistic modeling of young children's overall lead exposure in France: integrated approach for various exposure media. Environment International, 33, 937, 2007.

20. MESA-FRIAS M., CHALABI Z., VANNI T., FOSS A.M. Uncertainty in environmental health impact assessment: quantitative methods and perspectives. International Journal of Environmental Research and Public Health, 23, 16, 2012.

21. MARI M., NADAL M., SCHUHMACHER M., DOMINGO J.L. Exposure to heavy metals and PCDD/ Fs by the population living in the vicinity of a hazardous waste landfill in Catalonia, Spain: health risk assessment. Environment International, 35, 1034, 2009.

22. PHILIPPE G., NAWEL B., ALEXANDRA T., ALBAN R., BARBARA L.B., DENIS B. Probabilistic modeling of young children's overall lead exposure in France: integrated approach for various exposure media. Environment International, 33, 937, 2007.

23. SALOMONS W. Environmental impact of metals derived from mining activities: processes, predictions, prevention. Journal of Geochemical Exploration, 52, 5, 1995.

24. SHAO X., CHENG H., DUAN X., LIN C. Concentrations and chemical forms of heavy metals in agricultural soil near the world's largest and oldest tungsten mine located in China. Chemical Speciation and Bioavailability, 25, 125, 2013.

25. LU Y., SONG S., WANG R., LIU Z., MENG J., SWEETMAN A.J., JENKINS A., FERRIER R.C., LI H., LUO W., WANG T. Impacts of soil and water pollution on food safety and health risks in China. Environment International, 77, 5, 2015.
26. ZHAO F., MA Y., ZHU Y., TANG Z., MCGRATH S.P. Soil contamination in China: current status and mitigation strategies. Environmental Science and technology, 49, 750, 2015.

27. LIU X., TIAN G., JIANG D., ZHANG C., KONG L. Cadmium $(\mathrm{Cd})$ distribution and contamination in Chinese paddy soils on national scale. Environmental Science and Pollution Research, 23, 17941, 2016.

28. YANG Q., LI Z., LU X., DUAN Q., HUANG L., BI J. A review of soil heavy metal pollution from industrial and agricultural regions in China: Pollution and risk assessment. Science of the Total Environment, 642, 690, 2018.

29. HOU S., ZHENG N., TANG L., JI X., LI Y., HUA $\mathrm{X}$. Pollution characteristics, sources, and health risk assessment of human exposure to $\mathrm{Cu}, \mathrm{Zn}, \mathrm{Cd}$ and $\mathrm{Pb}$ pollution in urban street dust across China between 2009 and 2018. Environment International, 128, 430, 2019.

30. LI Z., MA Z., VAN DER KUIJP T.J., YUAN Z., HUANG L. A review of soil heavy metal pollution from mines in China: pollution and health risk assessment. Science of the Total Environment, 651, 3034, 2014.

31. YANG S., ZHAO J., CHANG S., COLLINS C., XU J., LIU X. Status assessment and probabilistic health risk modeling of metals accumulation in agriculture soils across China: A synthesis. Environment International, 128, 165, 2019.

32. LIU X., SONG Q., TANG Y., LI W., XU J., WU J., WANG F., BROOKES P.C. Human health risk assessment of heavy metals in soil-vegetable system, a multi-medium analysis. Science of the Total Environment, 463, 530, 2013.

33. PENA-FERNANDEZ A., GONZALEZ-MUNOZ M.J., LOBO-BEDMAR M.C. Establishing the importance of human health risk assessment for metals and metalloids in urban environments. Environment International, 72, 176, 2014.

34. MAN Y., SUN X., ZHAO Y., LOPEZ B.N., CHUNG S., WU S., CHEUNG K., WONG M. Health risk assessment of abandoned agricultural soils based on heavy metal contents in Hong Kong, the world's most populated city. Environment International, 36, 570, 2010.

35. CHEN H., TENG Y., LU S., WANG Y., WANG J. Contamination features and health risk of soil heavy metals in china. Science of the Total Environment, 512, $143,2015$. 